\title{
KHẢO SÁT KIẾN THỨC, THÁI Độ, HÀNH VI VỀ CHĂM SÓC TÂTT KHÚC XẠ CHO HỌC SINH TẠI 3 TỈNH HẢI DƯƠ'NG, ĐÀ NÃNG, TIỀN GIANG
}

\section{TÓM TẮT}

Mục tiêu: khảo sát kiến thức, thái độ, hành vi về chăm sóc tật khúc xạ (TKX) của học sinh̆ tiểu học và trung học cơ sở tại 3 tỉnh Tiền Giang, Đà Nẵng, Hải Dương. Đối tượng và phương pháp nghiên cứu: nghiên cứu phỏng vấn định tính KAP với 1.400 học sinh trên 36 trường học tại 3 tỉnh. Kết quả: về kiển thức, có $95,66 \%$ biết về "cận thị", 34,26\% biết khái niệm "viễn thị" và $45,12 \%$ về "loạn thị"; về thái độ: nói chung họ sinh có thái đô tích cực với việc đeo kính (điểm 3,56/ thang điểm 5); thực hành: tuần thủ đeo kính thấp (khoảng $1 / 2$ số học sinh có chỉ định đeo kính thường xuyên), nam tuân thủ thấp hơn nữ (16\% so với 4\% số học sinh không đeo kính trong cả tuân). Kết luận: cần tăng cường hoạt động truyền thông về chăm sóc mắt, phát triển tài liệu giảng day kiến thức, thái độ và thực hành về $T K X$ và chăm sóc mắt liên quan đến phòng tránh, điều chỉnh $T K X$ nhằm vào nhóm đối tượng học sinh tiểu học và trung học cơ sở.

Tư khóa: KAP, tật khúc xa

\section{SUMMARY}

KAP'S SURVEY OF REFRACTIVE ERRORS FOR CHILDREN IN HAIDUONG, DANANG, TIEN GIANG PROVINCES

Purpose: Survey the knowledge, attitude and practice regarding refractive errors in primary school and secondary school students in 3 provinces (2017). Materials and Method: KAP's quantitative interviews survey in 1,400 students in 3 provinces. Results: Knowledge: most students have heard about myopia (95.66\%) and a good proportion have already heard about hyperopia (34.26\%) and astigmatism (45.12\%); Attitudes: In general, students had positive attitudes toward spectacles wearing with an average score of 3.60 (the scale is within the range of 1 to 5), no difference between male and female students.; Practices: compliance by wearing spectacles is very poor: a half of RE students wearing prescripted spectacles regularly, male are less compliant than female students ( $16 \%$ versus $4 \%$ ). Conclusion: The following points regarding increasing RE's education and communication activities, and teaching materials on knowledge, attitudes and practices regarding refractive errors and eye care should be integrated in extra-scholar curriculum for primary and secondary school students.

Keywords: KAP, refractive errors

\footnotetext{
${ }^{1}$ Bệnh viện Mắt Trung ương ${ }^{2}$ Quỹ FHF Viêt Nam

Chịu trách nhiệm chính: Vũ Tuấn Anh

Email: vta.oph@gmail.com

Ngày nhận bài: 4.3.2021

Ngày phản biên khoa học: 26.4.2021

Ngày duyệt bài: 10.5.2021
}

\section{Vũ Tuấn Anh ${ }^{1}$, Phạm Quốc Ánh ${ }^{2}$}

\section{I. ĐĂT VẤN ĐỀ}

Tỷ lê học sinh Việt Nam mắc TKX khá cao, là gánh nặng kinh tế xã hội cũng như ảnh hưởng trực tiếp đến khả năng học tập của các cháu ${ }^{1}$. Kiến thức, thái độ và hành vi có ý nghĩa lớn trong chăm sóc TKKX. Trên thế giới, số lượng tương đối lớn các nghiên cứu về KAP của cộng đồng liên quan đến chăm sóc mắt đã được thực hiện, với một số nghiên cứu tập trung đặc biệt vào việc đeo kính. Agarwal and Dhoble (2013) ${ }^{2}$ tiến hành một nghiên cứu về liên quan đến TKX của học sinh ở khu vực nông thôn miền trung Ấn Độ và nhận thấy rằng sự thiếu hụt dinh dưỡng, thói quen chăm sóc mắt chưa tốt và di truyền là nguyên nhân dẫn đến tình trạng thị lực thấp ở đối tượng học sinh. Đáng chú ý, một tỷ lẹ lớn đối tượng được phỏng vấn tin rằng kính mắt có thể gây hại cho mắt. Kết quả này tương đồng với một nghiên cứu ở Nigeria (Ebeigbe, Kio \& Okafor $2013)^{3}$ trong đó một tỷ lệ lớn đối tượng nghiên cứu có thái độ tiêu cực đối với việc đeo kính.

Tại Việt Nam, một nghiên cứu về KAP của học sinh về TKX cho thấy kiến thức, thái độ và thực hành của những đối tượng này còn yếu. (Lê Thị Thanh Xuyên 2009) ${ }^{4}$. Tuy vậy, chưa có nghiên cứu nào tìm hiểu sâu về cách thức những yếu tố liên quan ảnh hưởng đến sức khỏe mắt của trẻ nhằm đưa ra chiến lược đúng đắn trong chăm sóc TKX cho trẻ em Việt Nam.

Vì vậy, nghiên cứu tiến hành trong khuôn khổ dự án của Quỹ FHF, nhằm xác định:

Thực trạng kiến thức, thái độ, hành vi trong chăm sóc tật khúc xạ cho học sinh tiểu học và trung học cở sở tại 3 tỉnh Tiền Giang, Đà Nẵng. Hải Dương năm 2017

\section{II. ĐỐI TƯỢNG VÀ PHƯƠNG PHÁP NGHIÊN CỨU}

Nghiên cứu tiến hành trên 1.400 học sinh của 35 trường tai 3 tỉnh thuộc dự án là Tiền Giang, Đà Nẵng. Hải Dương năm 2017.

Phương pháp nghiên cứu là phỏng vấn định lượng, nhằm phân tích kiến thức, thái độ, thực hành của học sinh.

Kiến thức, thái độ và thực hành của học sinh từ bảng hỏi định lượng được tính thành các chỉ số thống kê. Cụ thể hơn, về mặt thái độ, trong bảng hỏi định lượng, học sinh tham gia được hỏi về ý kiến về $T K X$ và việc đeo kính sử dụng thang đo Likert với 5 điểm phân loại, bao gồm "Hoàn 
toàn không đồng ý", "Không đồng ý", "Trung lập", "Đồng ý" và "Hoàn toàn đồng ý". Các câu trả lời được định lượng từ 1 đến 5 . Điểm này được tính trung bình thành một chỉ số để đo lường thái độ của mỗi người trả lời về việc đeo kính. Điểm cao hơn thể hiện thái độ tích cực hơn về việc đeo kính.

\section{KẾT QUẢ NGHIÊN CỨU VÀ BÀN LUÂNN}

3.1. Tỷ lệ tham gia khảo sát. Khoảng 75,19\% học sinh trong danh sách mẫu chính thức tham gia phỏng vấn định lượng. Tỷ lệ trả lời ở các tỉnh là khá giống nhau trong khu vực thuộc dự án (Bảng 3.1.1).

Bảng 3.1.1. Tý lê tham gia của học sinh trong khảo sát (\% của mâuu chính thức)

\begin{tabular}{|c|c|c|}
\hline Địa điểm & $\begin{array}{c}\text { Sàng lọc } \\
\text { thị lực } \\
(\%)\end{array}$ & $\begin{array}{c}\text { Phỏng vânn } \\
\text { định lượng } \\
(\%)\end{array}$ \\
\hline Tống (Vùng dự án) & 88,90 & 75,19 \\
\hline Hải Dương & 86,35 & 77,81 \\
\hline
\end{tabular}

\begin{tabular}{|c|c|c|}
\hline Đà Nằng & 86,12 & 71,19 \\
\hline Tiền Giang & 94,23 & 76,88 \\
\hline Ngoài dự án(Đà Nằng) & 99,69 & 72,78 \\
\hline
\end{tabular}

3.2. Kiến thức về tật khúc xa. Nhân biết tật khúc xạ, cách phòng tránh và điều chỉnh tật khúc xa

Tại các trường thuộc dự án CSMHĐ tham gia khảo sát, trung bình $23,65 \%$ học sinh đã nghe tới cụm từ "tật khúc xạ" (cao hơn rất nhiều ở các trường khổng có dự án, 4,60\%). Đối với từng loại TKX, hầu hết học sinh đã từng nghe tới cụm từ "cận thị" (95.66\%) và một tỳ lệ không nhỏ đã nghe tới "viễn thị" (34,26\%) và "loạn thị" $(45,12 \%)$ (Biểu đồ 3.2.1). Trung bình, tỳ lệ học sinh tại Tiền Giang có kiến thức về TKX thấp hơn rõ் rệt so với Đà Nẵng và Hải Dương. Tương tự, tỷ lệ học sinh biết về các loại TKX ở nông thôn thấp hớn so với thành thị. Tuy nhiên, sự khác biệt giữa tỷ lệ học sinh nam và tỷ lệ học sinh nữ từng nghe đến các loại TKX là không đáng kể.

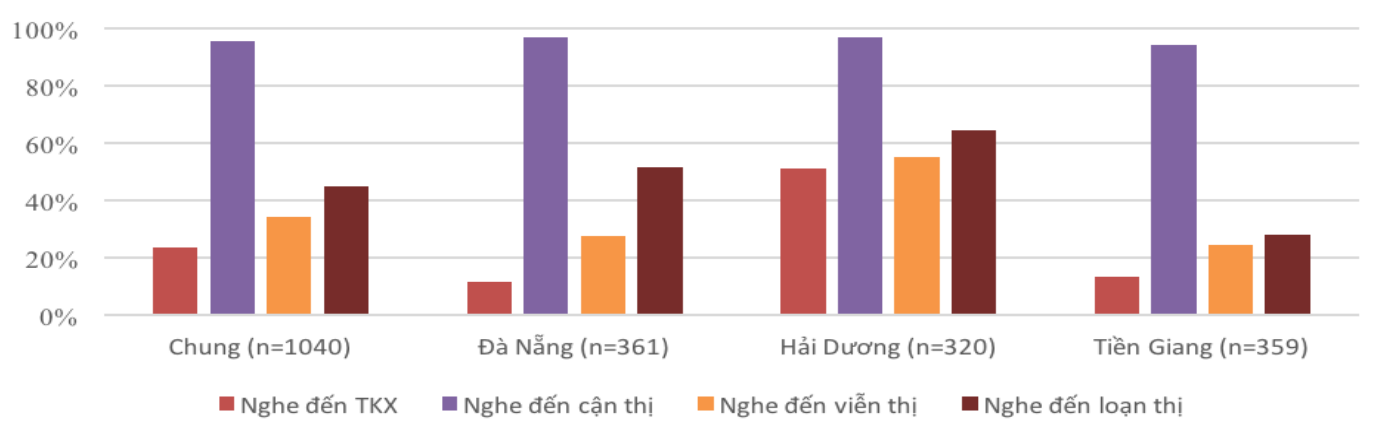

Biểu đồ 3.2.1. Tỷ lệ học sinh biêt đến các tật khúc xạ theo tỉnh thành

Học sinh biết đến dấu hiệu nhận biết cận thị nhiêu hơn so với viễn thi và loan thi. Đối với hoc sinh, "nhìn không rõ" là cách nhận biết phổ biến nhất về TKX. Mặc dù trên $80 \%$ số học sinh biết đến cận thị nhắc đến triệu chứng này, chỉ khoảng $30 \%$ đề câp tới biểu hiện này là của viễn thị và loạn thị. $10 \%$ học sinh nhận biết được các biểu hiện khác của TKX. Không có sự khác biệt giữa tỳ lệ học sinh nam và tỷ lệ học sinh nữ trong cách nhận biết, phòng tránh và điều chỉnh TKX.

Tương tự như dấu hiệu nhận biết TKX, cách điều chỉnh cận thị được nhiều học sinh biết đến nhiều hơn so với cách điều chỉnh viến thị và loạn thị. Đa số các học sinh nhắc đến việc đeo kính là cách thức để chữa trị tật cận thị (trong 88,61\% số học sinh đã nghe về TKX này). Tuy nhiên, chỉ $33,69 \%$ trong số các em đã nghe về viễn thị biết đến kính là cách điều trị tật này. Bên cạnh đó, một số học sinh nhận thức sai rằng uống thuốc (khoảng 6\%) hoặc luyện tập mắt (khoảng 1,5\%) là cách điều trị phù hợp. Khoảng $10 \%$ hoc sinh tin rằng đi khám bác sĩ hoặc đơn giản là nhìn gần hơn là những cách điều trị phù hợp cho cận thị hoặc loạn thị. Nhận thức này phổ biến hơn tại khu vực thành thi. Mặc dù điều chỉnh TKX bằng cách "nhìn gần hơn" là sai, nhận thức này còn khá phổ biến trong nhóm học sinh. Điều này cho thây tỷ lệ lớn học sinh còn thiếu kiến thức cơ bản về điểu chỉnh TKX.

Cách phòng tránh cận thị cũng được học sinh biết đến nhiều hơn so với phòng tránh viễn thị và loạn thị (Biểu đồ 3.2.2). Phần lớn học sinh đều đưa ra được nhiều hơn môt phương pháp đúng nhằm hạn chế mắc cận thị, nhưng trên $75 \%$ học sinh không thể kể lấy được một phương pháp phòng tránh viến thị hoặc loạn thị. Những phương án phòng ngừa cận thị được hoc sinh đưa ra nhiều nhất ở Hải Dương và Tiền Giang là ngồi học đúng tư thế (lần lượt là 
55,89\% và 33,58\%); giảm thời gian xem TV và thiết bị điện tử (lân lượt là 53,89\% và 32,04\%); và cho mắt nghỉ 5 đến 10 phút sau 45 phút đọc hoặc làm việc với thiết bị điện tử (lân lượt là $33,74 \%$ và $22,53 \%$ ). Những phương pháp trên được học sinh Hải Dương đưa ra nhiêuu hơn hẳn ở Tiền Giang và ở Đà Nẳng, ngoại trừ việc giảm thời gian sử dụng các thiết bị điện tử được $58,91 \%$ học sinh Đà Nẵng đưa ra. Phân lớn học sinh không biết rằng sử dụng bảng chống lóa $(0,00 \%)$, hoạt động thể lực ngoài trời, bổ sung đủ dinh dưỡng, hay khám mắt 6 tháng 1 lần là cách giúp phòng tránh TKX.

Đáng chú ý, có một tỷ lệ không nhỏ học sinh có kiến thức sai hoặc hiều sai về cách phòng tránh TKX. Ví dụ điển hình, có đến 40,24\% học sinh ở Đà Nẵng cho rằng việc xem TV từ khoảng cách xa hơn là phương pháp phòng tránh TKX phù hợp. Nhận thức này phổ biến hơn rất nhiêu tại khu vực thành thi $(35,41 \%)$ so với khu vực nông thôn $(17,44 \%)$.

Tỷ lệ học sinh nữ không biết đến cách phòng tránh loạn thị cao hơn rõ rệt so với học sinh nam (85,03\% so với 74,98\% học sinh nam không biết) và trong số những học sinh có kiến thức về phòng chống loạn thị, tỷ lệ học sinh nam đưa ra biện pháp giảm thời gian sử dụng các thiết bị điện tử nhiều hơn hẳn tỷ lệ học sinh nữ. Tỷ lệ học sinh nông thôn và tỷ lệ học sinh ngoài vùng dự án không có kiến thức về phòng tránh TKX cào hơn rõ rệt so với khu vực thành thị và vùng dự án.

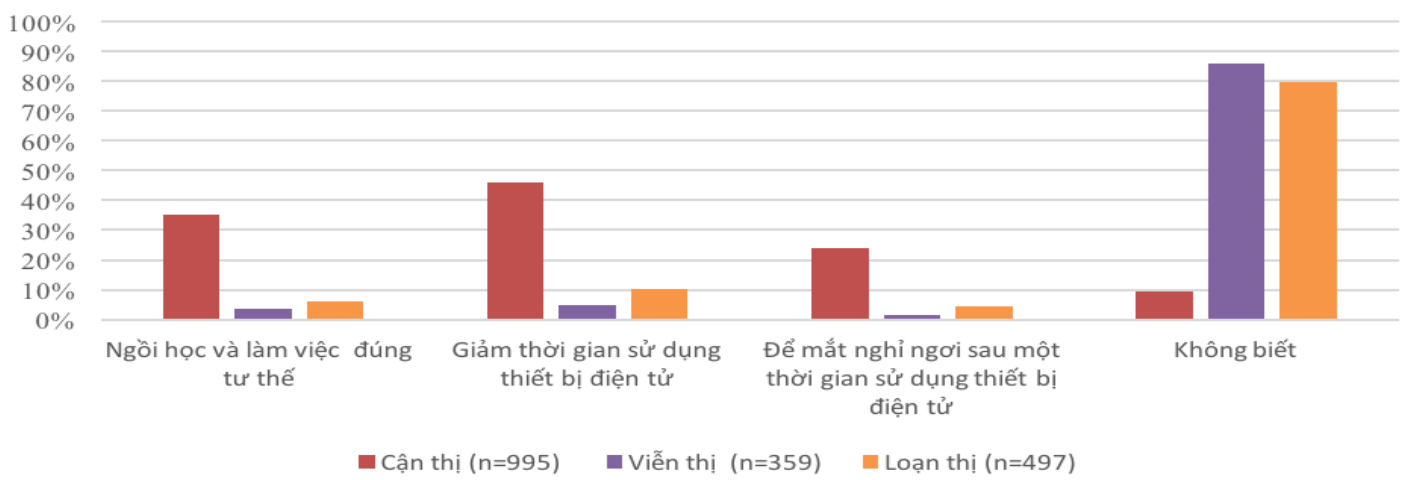

Biểu đồ 3.2.2. So sánh các biện pháp phòng chống TKX phổ biến được học sinh đưa ra

3.3. Thái độ với việc đeo kính. Nhìn chung, học sinh có thái độ tích cực đối với việc đeo kính. Điểm thái độ trung bình đạt 3,56 (thang điểm từ 1 đến 5). Trong 3 tỉnh có dự án CSMHĐ, học sinh Tiền Giang $(3,60)$ có thái độ tích cực nhất so với học sinh Đà Nẵng $(3,55)$ và Hải Dương $(3,50)$. Thái độ khác biệt giữa học sinh nam và học sinh nữ là rất thấp $(3,55$ và 3,56$)$. Học sinh tiểu học và học sinh vùng nông thôn có thái độ tích cực hơn so với học sinh bậc trung học cở sở và thành thị (Biểu đồ 3.3.1).

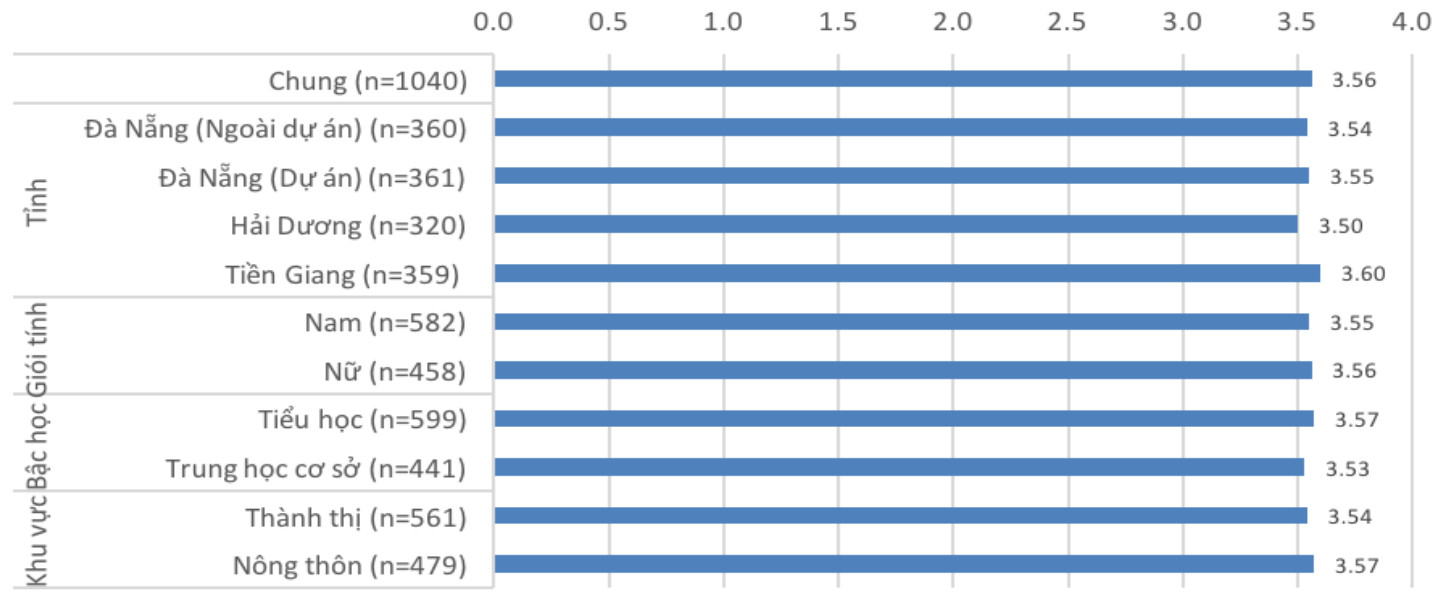

Biểu đồ 3.3.1. Thái độ của học sinh về việc đeo kính 
Quan điểm tiêu cực của trẻ về việc đeo kính thể hiện rõ nét ở phỏng vấn định tính và thảo luận nhóm tập trung. Trẻ được trả lời phỏng vấn chỉ ra những định kiến và những biệt danh bị trêu chọc, như "mù", "bốn mắt", "đầu to mắt cận" và "đeo đít chai" khi các em đeo kính điêu chỉnh TKX. Những quan điểm tiêu cực về việc đeo kính trong nghiên cứu này cũng khá tương đồng với kết quả của nghiên cứu về kiến thức, thái đô và thực hành về sức khoẻ mắt được thực hiện ở Nigeria (Ebeigbe, J.A., Kio, F., and Okafor, L.I., 2013) ${ }^{3}$. Trong đó, một số quan điểm tiêu cực phổ biến trong dư luận ở Nigeria, bao gồm "kính mắt có hại cho mắt", "những người đeo kính bị coi là tàn tật thị lực", "Người đeo kính thường bị trêu choc" và "kính mắt chỉ dành cho người già ".

3.4. Thực hành chăm sóc mắt (tât khúc xạ). Trong số các học sinh được phỏng vấn
(1040 hoc sinh), 11\% số này cho biết em được chỉ định đeo kính để điều trị các TKX. Tỷ lệ học sinh tiểu học có chỉ định đeo kính thấp hơn so với học sinh trung học cơ sở (8\% so với 15\%). Tương tự, tỷ lệ học sinh nông thôn có chỉ định đeo kính thấp hơn so với học sinh thành thị (6\% và $17 \%)$.

Trong số những học sinh được chỉ định đeo kính, tỉ lệ tuân thủ việc đeo kính còn rất thấp (Biểu đồ 3.4.1). Chỉ một nửa số học sinh đeo kính theo chỉ định một cách thường xuyên hoặc liên tục, khoảng $10 \%$ các em không đeo kính trong suốt cả tuần. Khoảng hai phần ba số học sinh ở Đà Nẵng và Tiền Giang đeo kính thường xuyên hoặc liên tục theo chỉ định y khoa, tỷ lệ này cao hơn rất nhiều so với Hải Dương. Học sinh nam ít tuân thủ đeo kính hơn học sinh nữ (16\% so với $4 \%$ số học sinh không đeo kính trong cả tuần).

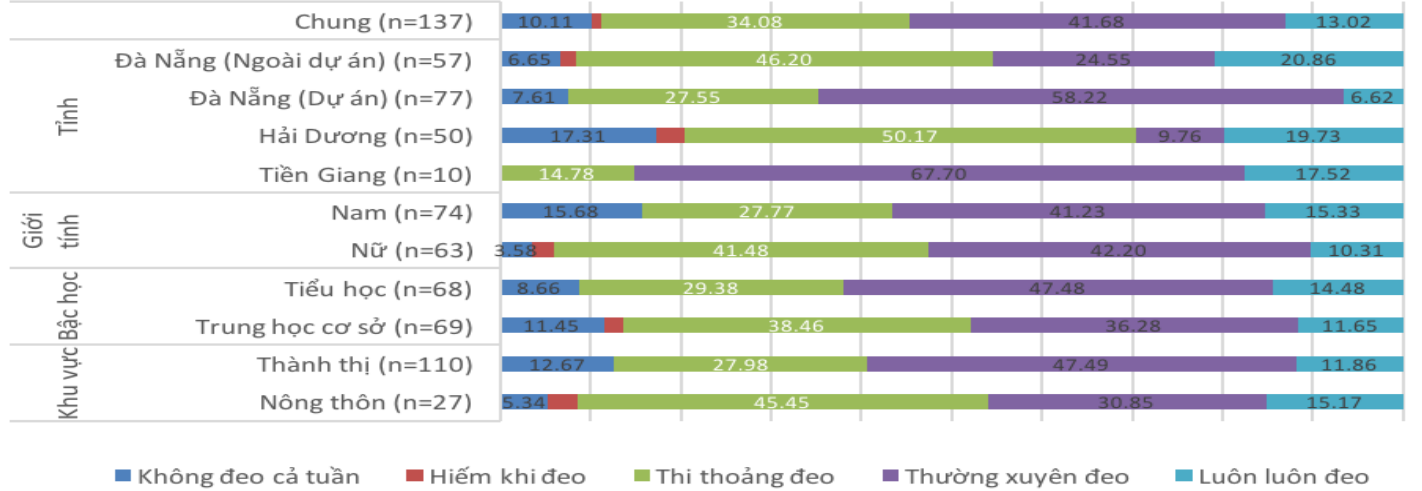

Biểu đồ 3.4.1. Tân suất đeo kính của học sinh trong tuân

Học bài và xem các thiết bi điên tử là thời điểm các em học sinh đeo kính ( $99 \%$ ở Hải Dương và Tiền Giang và $68,80 \%$ ở Đà Nẵng). Tại Tiền Giang, 84,69\% học sinh đeo kính khi đọc sách, gấp 2,5 lần so với Đà Nẵng và Hải Dương. Tỳ lệ học sinh nông thôn đeo kính lúc học bài cao hơn so với tỷ lệ này ở thành phố $(98,33 \%$ so với $73,41 \%)$.

Học sinh giữa các tỉnh đưa ra các lý do khá giống nhau giải thích cho việc không đeo kính. Kính không cần thiết $(29,38 \%)$ và/hoặc không tiện lợi $(33,93 \%)$ là hai lý do chính dẫn đến học sinh chọn không đeo kính. Một số ít học sinh đề cập đến lý do "đeo kính có hại cho mắt nên không đeo", đây là nhận thức sai lầm dẫn đến hành vi không tuân thủ đeo kính như chỉ định của bác sỹ. Tỷ lệ học sinh tỉnh không có dự án CSMHĐ nghĩ kính không cần thiết cao hơn so với khu vực tỉnh có dự án CSMHĐ. Đáng chú ý là có đến $11,18 \%$ số học sinh khu vực thành thị không đeo kính vì cho rằng kính có hại cho mắt, trong khi không có học sinh nào ở nông thôn lựa chọn lý do này. Không có sự khác biệt giữa học sinh nam và học sinh nữ liên quan đến ký do giải thích cho việc không đeo kính.

Bảng 3.4.1. Lý do học sinh không đeo kính

\begin{tabular}{|c|c|c|c|c|c|c|}
\hline Các lý do & $\begin{array}{c}\text { Không } \\
\text { thuâân tiện, } \\
\text { vướng víu }\end{array}$ & $\begin{array}{c}\text { Không cần } \\
\text { thiết phải } \\
\text { đeo }\end{array}$ & $\begin{array}{c}\text { Cảm thấy } \\
\text { không tự tin } \\
\text { khi đeo kính }\end{array}$ & $\begin{array}{c}\text { Bố me bảo bôn đeo } \\
\text { không đeo }\end{array}$ & $\begin{array}{c}\text { Deo kính có } \\
\text { thể hại cho } \\
\text { mắt }\end{array}$ & $\begin{array}{c}\text { Quên } \\
\text { không đeo }\end{array}$ \\
\hline Chung (n=116) & 33,93 & 29,38 & 4,63 & 8,08 & 7,38 & 5,11 \\
\hline Tỉnh: Đà Năng (Ngoài dự & 36,21 & 49,04 & 5,20 & 14,69 & 8,21 & 12,42 \\
\hline
\end{tabular}


TẠP CHÍ Y HỌC VIẸT NAM TẬP 502 - THÁNG 5 - SÓ 2 - 2021

\begin{tabular}{|c|c|c|c|c|c|c|}
\hline án) ( $\mathrm{n}=45)$ & & & & & & \\
\hline Đà Năng (Dự án) $(\mathrm{n}=71)$ & 39,51 & 23,38 & 1,10 & 8,36 & 14,07 & 0.00 \\
\hline Hải Dương $(\mathrm{n}=37)$ & 23,21 & 32,68 & 10,89 & 10,85 & 0.00 & 13,19 \\
\hline Tiền Giang $(\mathrm{n}=8)$ & 39,35 & 44,30 & 2,52 & 0,00 & 0.00 & 4,54 \\
\hline Giới: Nam $(\mathrm{n}=61)$ & 37,00 & 33,73 & 7,71 & 8,58 & 7,32 & 2,29 \\
\hline Nữ ( $\mathrm{n}=55)$ & 30,54 & 24,56 & 1,21 & 7,52 & 7,43 & 7,46 \\
\hline Bậc học & & & & & & \\
\hline Tiếu học $(\mathrm{n}=55)$ & 32,34 & 30,74 & 1,12 & 6,88 & 5,58 & 0,76 \\
\hline Trung học cơ sở $(\mathrm{n}=61)$ & 35,37 & 28,14 & 7,79 & 9,15 & 8,99 & 9,03 \\
\hline Khu vực & & & & & & \\
\hline Thành thị $(\mathrm{n}=93)$ & 33,37 & 23,01 & 0,87 & 7,86 & 11,18 & 0,55 \\
\hline Nông thôn $(\mathrm{n}=23)$ & 35,02 & 41,71 & 11,90 & 8,50 & 0.00 & 13,95 \\
\hline
\end{tabular}

\section{KẾT LUÂ̂N}

Kiến thức, thái độ và thực hành của học sinh tiểu học và trung học cơ sở liên quan đến tật khúc xạ và sức khoẻ mắt còn ở mức khá khiêm tốn, đòi hỏi cần tăng cường hoạt động truyền thông về chăm sóc mắt góp phần cải thiện kiến thức, thái độ và thực hành cho nhóm đối tượng trên. Ngoài ra có thể phát triển tài liệu giảng dạy kiến thức, thái độ và thực hành về tật khúc xạ và chăm sóc mắt liền quan đến phòng tránh, điều chỉnh tật khúc xạ nhằm vào nhóm đối tượng học sinh tiểu học và trung học cơ sở.

\section{TÀI LIỆU THAM KHẢO}

1. Paudel, P., Ramson, P., Naduvilath, T.,
Wilson, D., Phuong, H. T., Ho, S. M., \& Giap, N. V. (2014). Prevalence of vision impairment and refractive error in school children in Ba RiaVung Tau province, Vietnam. Clinical \& experimental ophthalmology, 42(3), 217-226.

2. Agarwal, R. \& Dhoble, P.' (2013). Study of the Knowledge, Attitude and Practices of Refractive Error with Emphasis on Spectacle Usages in Students of Rural Central India. Journal of Biomedical and Pharmaceutical Research, 2(3), 150-154

3. J A Ebeigbe, F Kio, L I Okafor (2013). Attitude and Beliefs of Nigerian Undergraduates to Spectacle Wear. Ghana Med J. ; 47(2): 70-73.

4. Lê Thị Thanh Xuyên, Bùi Thị Thu Hương, Phí Duy Tiến (2009). Prevalence of Refractive error and Knowledge, Attitudes and Self Care Practices Associated with Refractive Error in Ho Chi Minh City. Y Hoc TP. Ho Chi Minh. 13(1). 13-25.

\section{ĐÁNH GIÁ KẾT QUẢ ĐIỀU TRİ BỆNH MÀNG TRONG Ở TRẺ SƠ SINH NON THÁNG BẰNG LIỂU PHÁP SURFACTANT TẠI BỆNH VIỆN SẢN-NHI TỈNH QUẢNG NGÃI}

\section{TÓM TẮT}

Đặt vấn đề: Bệnh màng trong hay còn gọi là Hội chứng suy hô hấp là bệnh lý khá phổ biến ở trẻ sớ sinh, đặc biệt ở trẻ sơ sinh non tháng, nguyên nhân là do thiếu chất hoạt diện (Surfactant) ở phổi. Tại Bệnh viện Sản-Nhi Quảng Ngãi, Surfactant ngoai sinh đã được đưa vào sử dụng từ lâu, tuy nhiên việc điều trị đa phân chưa đạt kết quả cao. Chúng tôi mong muốn đánh giá kết quả sử dụng liệu pháp Surfactant thay thế trong điều trị Bệnh màng trong. Mục tiêu: Mô tả đặc điểm lâm sàng, cận lâm sàng và một số yếu tố liển quan về Bệnh màng trong ở trẻ sơ sinh non tháng. Đánh giá kết quả điều trị Bệnh màng trong ở

${ }^{1}$ Bệnh viện Sản-Nhi tỉnh Quảng Ngãi

Chịu trách nhiệm chính: Nguyển Đình Tuyến

Email: nguyendinhtuyen889@gmail.com

Ngày nhận bài: 2.3.2021

Ngày phản biên khoa học: 27.4.2021

Ngày duyệt bài: 11.5.2021

\section{Phạm Vân Anh ${ }^{1}$, Nguyễn Đình Tuyến ${ }^{1}$}

trẻ sơ sinh non tháng bằng liệu pháp Surfactant. Đối tượng và phương pháp nghiên cứu: Nghiên cứu cắt ngang mô tả, hồi cứu toàn bô hồ sơ bệnh án của trẻ sơ sinh non tháng được chẩn đoán Bệnh màng trong, chỉ định điều trị thay thế bằng Surfactant tại khoa Sơ sinh, Bệnh viện Sản-Nhi Quảng Ngãi từ 01/01/2019 đến 30/06/2020. Kết quả: Tỷ lệ nam/nữ là $1 / 1,1$; tuổi thai rất non $<32$ tuần là $63,2 \%$, trung bình 30,1 3,1 tuần; cân nặng chủ yếu <2000 gr chiếm 73,6\%, cân nặng lúc sinh trung bình là $1521 \pm$ 588 gr. Các dấu hiệu suy hô hấp xuất hiện sớm, có $47,4 \%$ trẻ được hồi sức đă̆t nội khí quản lúc nhập khoa, thở rên $(60 \%)$, hạ thẩn nhiệt $(71,9 \%)$, rối loạn nhịp thở $(63,3 \%)$, tím $(40,4 \%)$. pH giảm nặng dưới 7,25 chiếm $56,1 \%$, giảm oxy hóa máu từ nhẹ đến nặng là $82,5 \%$. Tổn thương trên Xquang phổi độ II-III chiếm $77,2 \%$. Giới tính là liên quan có ý nghĩa thống kê với mức độ nặng của Bệnh màng trong trên Xquang. Surfactant có hiệu quả rõ rệt khi nhu câu Oxy và tình trang toan hô hấp máu được cải thiện nhanh chóng sau bơm 1 giờ. X-quang phổi cải thiện $96,5 \%$ 